\title{
Abrogation of Macrophage-dependent Injury in Experimental Glomerulonephritis in the Rabbit
}

\author{
USE OF AN ANTIMACROPHAGE SERUM \\ Stephen R. Holdsworth, T. James Neale, and Curtis B. Wilson, Department \\ of Immunopathology, Research Institute of Scripps Clinic, \\ La Jolla, California 92037
}

\begin{abstract}
A B S TRACT Macrophages were shown by the use of glomerular cell culture and morphologic techniques to be present in large numbers within the glomeruli of rabbits with acute serum sickness (AcSS) and in a passive model of the autologous phase of antiglomerular basement membrane (GBM) antibodyinduced glomerulonephritis (PAGBMN). To determine the part played by these cells in the glomerular injury, animals were treated with a sheep anti-rabbit macrophage serum (AMS) or normal sheep serum (NSS). NSS administration had no effect on the development of either model of glomerulonephritis. The use of AMS reduced the number of circulating monocytes and prevented the accumulation of macrophages within glomeruli in both models (AcSS/NSS, mean 126/glomerulus, range 40-251; AcSS/AMS, mean 8 , range 1-44; PAGBMN/NSS, mean 52, range 27-69; PAGBMN/AMS, mean 5, range 2-7). The AMS-treated rabbits had only minor histologic lesion and profound reduction in proteinuria (AcSS/NSS, mean $516 \mathrm{mg} / 24 \mathrm{~h}$, range 200-991; AcSS/AMS, mean 41, range 3-161; PAGBMN/NSS, mean 335, range 55-975; PAGBMN/AMS, mean 10, range 2-24). Similar studies in the heterologous phase of glomerular injury induced by the same anti-GBM antibody revealed no effect of the AMS on this polymorpho-
\end{abstract}

This work was presented in 1980 at the American Society of Nephrology Meeting and published in abstract form in 1981. Kidney Int. 19: 193.

Dr. Holdsworth was the recipient of a fellowship from the National Kidney Foundation; his current address is Department of Medicine, Prince Henry's Hospital, Melbourne, Australia. Dr. Neale's current address is Department of Medicine, Wellington Public Hospital, Wellington, New Zealand. Address reprint requests to Curtis B. Wilson, M. D., Department of Immunopathology, Research Institute of Scripps Clinic, La Jolla, Calif. 92037

Received for publication 20 January 1981 and in revised form 15 May 1981 nuclear leukocyte-related phase of injury, demonstrating the selectivity of the antisera. Complement depletion, with cobra venom factor, did not affect the development of glomerulonephritis nor the accumulation of macrophages in either model. Inhibition of macrophage accumulation can largely prevent these forms of experimental glomerulonephritis, thereby implicating macrophages as mediators of glomerular injury and consequent proteinuria.

\section{INTRODUCTION}

Several mediators of inflammation, including the polymorphonuclear leukocyte $(\mathrm{PMN})^{1}(1,2)$ the complement $(1,3)$, and the coagulation system $(4,5)$, are capable of producing glomerular injury in experimental immunologic glomerulonephritis. The ability of these mediators to promote glomerular injury has been defined in large part by observing the effects of their selective depletion before or during the development of the experimental lesion (1-6). Additional systems remain to be defined because some experimental immunologic glomerulonephritis, for example, acute serum sickness (AcSS) $(3,6)$ and certain forms of antiglomerular basement membrane (GBM) antibodyinduced disease, occur in the absence of complement and PMN (7).

Recently, macrophages have been identified in immunologically initiated glomerular injury such as acute $(8,9)$ and chronic (10) proliferative glomerulonephritis in man, and in experimental animal models

\footnotetext{
${ }^{1}$ Abbreviations used in this paper: AcSS, acute serum sickness; AMS, anti-rabbit macrophage serum; BSA, bovine serum albumin; FCS, fetal calf serum; GBM, glomerular basement membrane; MEM, minimum essential medium; NSS, normal sheep serum; PAGBMN, passive model of the autogologous phase of anti-GBM antibody-induced glomerulonephritis; PMN, polymorphonuclear leukocyte.
} 
including anti-GBM antibody-induced disease in rabbits (11) and rats $(12,13)$, "autoimmune" glomerulonephritis in sheep (11), immune complex-mediated glomerulonephritis, e.g., acute $(14,15)$ and chronic (15) serum sickness in rabbits, as well as passive serum sickness in mice $(16,17)$. Beyond its presence, the functional importance of the macrophage has not been extensively explored. Depletion of inflammatory cells by irradiation suggests that monocytes play a role in an augmented autologous phase of anti-GBM antibodyinduced glomerulonephritis in rats (12). Also, the use of an antilymphocyte serum with activity against lymphocytes and esterase-positive cells substantially decreased $24 \mathrm{~h}$ proteinuria and the glomerular ingress of mononuclear cells appearing within $30 \mathrm{~min}$ of the injection of heterologous anti-GBM antibody to rats (18).

Our recent findings of a close temporal relationship between macrophage accumulation and extent of glomerular damage in acute (and chronic) serum sickness suggests that macrophages play a significant role in these models of experimental immune complex glomerulonephritis (15). To establish the role of macrophage infiltration in glomeruli as a major mediator of glomerular damage, independent of the PMN, an antimacrophage serum (AMS) was used to block macrophage accumulation in glomeruli. Previously, AMS has been used by others to examine the function of macrophages in vivo (19-21) in various situations. The AMS used had no detectable effect on in vitro PMN function or on the PMN-related heterologous phase of experimental anti-GBM antibody-induced glomerulonephritis. It did, however, abrogate two forms of experimental glomerulonephritis in which macrophages are present in glomeruli in large numbers, in close association with the timing and extent of proteinuria and glomerular injury: $(a) \mathrm{AcSS}$ (b) passive autologous anti-GBM antibody-induced glomerulonephritis (PAGBMN).

\section{METHODS}

PAGBMN. Male New Zealand White rabbits $(1.8-2.5 \mathrm{~kg})$ were used. A subnephritogenic dose $(7.2 \mu \mathrm{g} / \mathrm{g}$ kidney) of horse anti-rabbit GBM antibody was administered intravenously. $15 \mathrm{~h}$ later, rabbit anti-horse gamma globulin antibody directed against the "planted" horse antirabbit GBM antibody was administered, sufficient to bind a mean of $5.8 \mu \mathrm{g}$ rabbit anti-horse gamma globulin antibody/g kidney (range 5.1-6.8 $\mu \mathrm{g}, n=4$ ). Quantitation of binding was done by the paired label isotope technique (22). The model was examined at five time points in groups of four rabbits: killed $2 \mathrm{~h}$ after horse anti-rabbit GBM antibody, injection immediately before the administration of rabbit anti-horse gamma globulin antibody, and 2,12 , and $24 \mathrm{~h}$ later. The horse anti-rabbit GBM antibody was prepared by repeated immunization with particulate rabbit renal basement membrane in complete Freund's adjuvant. The antiserum was decomplemented $\left(56^{\circ} \mathrm{C}\right.$ for $\left.30 \mathrm{~min}\right)$ and absorbed with rabbit serum and erythrocytes. Normal horse gamma globulin was used as immunogen to produce the rabbit anti-horse gamma globulin antibody in rabbits. Globulin fractions of the antisera were prepared by repeated precipitation in a final concentration of $50 \%$ saturated ammonium sulfate.

Circulating leukocyte depletion was accomplished in six rabbits given nitrogen mustard $(1.75 \mathrm{mg} / \mathrm{kg}$ i.v. and $1 \mathrm{mg} / \mathrm{kg}$ $36 \mathrm{~h}$ later) to lower their total leukocyte counts to $<1,000$ cells $/ \mathrm{mm}^{3}$, PMN, lymphocyte, and monocyte counts each being reduced by at least $80 \%$ before horse anti-rabbit GBM antibody was given. Macrophage involvement was assessed in 12 rabbits, using AMS (100 mg) administered intraperitoneally twice daily beginning $2 \mathrm{~h}$ before the injection of horse anti-rabbit GBM antibody. Six additional rabbits received equivalent amounts of normal sheep serum (NSS) as controls. Seven rabbits had prior depletion of (third component of complement) C3 by administration of cobra venom factor (23). The amount of proteinuria (24), light and electron microscopic appearances of the glomeruli, number of PMN per glomerular cross section, number of glomerular macrophages recovered by culture, deposition of rabbit IgG, $\mathrm{C} 3$, and horse IgG in glomeruli, levels of circulating leukocytes, and $\mathrm{C} 3(25)$, and $\mathrm{CH}_{50}(6)$ were determined, where appropriate.

AcSS. An augmented model of AcSS was induced in $1.8-2.5 \mathrm{~kg}$ male New Zealand White rabbits by intravenous administration of $250 \mathrm{mg}$ trace radiolabeled bovine serum albumin (BSA) per kilogram $15 \mathrm{~h}$ after an intravenous dose of $2.5 \mathrm{mg}$ protein nitrogen anti-BSA antibody/ $\mathrm{kg}(15,26)$. Rabbits with immune elimination of $>99 \%$ of circulating BSA between 9 and $12 \mathrm{~d}$ had more severe and homogeneous glomerular injury than those eliminating later (26) and were therefore chosen for study. Rabbits were randomly allocated to treatment with $200 \mathrm{mg}$ i.p. twice daily of either AMS (eight rabbits) or NSS (six rabbits), or were given no treatment (six rabbits). All rabbits included had treatment initiated 2 or $3 \mathrm{~d}$ before the estimated day of immune elimination. The clearance of BSA, levels of circulating BSA-anti-BSA immune complexes (27), proteinuria, levels of circulating leukocytes, light and electron microscopic appearances of the kidney, number of glomerular macrophages in culture, and deposition of BSA, IgG, and C3 were compared between groups.

The effect of complement depletion on macrophage accumulation was studied in seven rabbits developing AcSS by giving cobra venom factor (23) beginning 3-5 $\mathrm{d}$ before immune elimination. $\mathrm{C} 3$ and $\mathbf{C H}_{50}$ levels were measured daily. Six of the seven treated animals cleared the injected BSA between 9 and $12 \mathrm{~d}$ and the disease in these rabbits was assessed as for the other AcSS animals.

Heterologous phase anti-GBM antibody-induced glomerular injury. To evaluate the effect of the AMS on a predominantly PMN-dependent model of experimental glomerulonephritis, rabbits were given intravenously $40 \mu \mathrm{g} / \mathrm{g}$ of horse kidney anti-rabbit GBM antibody. Six rabbits received nitrogen mustard as described above, six received AMS $(200 \mathrm{mg} 2 \mathrm{~h}$ before and $10 \mathrm{~h}$ after the horse anti-rabbit GBM antibody), and six were untreated. Proteinuria (24) was measured over the subsequent $24 \mathrm{~h}$, the rabbits killed, and morphologic damage and number of macrophages per glomerulus determined. Eight additional rabbits (four treated with $200 \mathrm{mg}$ AMS i.p.) received the same dose of horse antirabbit GBM antibody and were examined $2 \mathrm{~h}$ later to assess the accumulation of PMN.

Glomerular cell culture to quantitate glomerular macrophages. Glomeruli were cultured and the number of macrophages present in the outgrowths of individual glomeruli determined $(11,15,28,29)$. Portions of kidney cortex were collected in a sterile manner and glomeruli were isolated and cultured individually in a drop of culture medium 
(minimum essential medium [MEM] Flow Laboratories, Rockville, Md.) containing $10 \%$ fetal calf serum (FCS). The number of macrophages detected after $4 \mathrm{~d}$ in culture was expressed as the mean from outgrowths of 15 individual glomeruli. Previous studies have clearly shown enumerated cells to be macrophages based on their ultrastructural appearance, motility, phagocytic activity, and presence of Fc receptors $(11,28,29)$.

\section{AMS}

Preparation. Rabbit peritoneal macrophages were harvested in a sterile manner $3 \mathrm{~d}$ after the instillation of $3 \%$ thioglycolate (BBL Microbiology Systems, Becton, Dickinson and Co., Cockeysville, Md.). After washing in MEM containing FCS (Flow Laboratories), the cells were placed in $150 \mathrm{~cm}^{2}$ flasks (Corning Glass Works, Science Products Div., Corning, N. Y.) containing MEM and 10\% FCS. $4 \mathrm{~h}$ later and daily for $3 \mathrm{~d}$, the flasks were washed with MEM to remove nonadherent cells. The adherent macrophages (>98\% mononuclear cells on Wright's stain) were recovered, washed, and incorporated into Freund's complete adjuvant. Two sheep were injected, each, every $2 \mathrm{wk}$, over a 10 mo period with a total of $10^{9}$ macrophages. Pooled serum from the immunized sheep was adsorbed extensively with rabbit plasma, red cells, PMN, and platelets until nonreactive with these elements, as described below. A globulin fraction was prepared by repeated precipitation in a final concentration of $50 \%$ saturated ammonium sulfate. As a control, a pool of NSS was absorbed and precipitated with saturated ammonium sulfate in a manner similar to the AMS. The presence of albumin in the saturated ammonium sulfate precipitates was assessed by double immunodiffusion in $1 \%$ agar.

Assessment in vitro. The effects of AMS on macrophages harvested from rabbit's peritoneum, as described above, and PMN obtained from the peritoneum of other rabbits $4 \mathrm{~h}$ after the i.p. injection of glycogen $(50 \mathrm{ml} / \mathrm{kg}, 0.1 \%, \mathrm{~J}$. T. Baker Chemical Co., Phillipsburg, N. J.) were assessed. Spleen cells were teased from fresh normal rabbit spleens and passed through glass wool to remove adherent cells. Mononuclear cells were purified from heparinized blood by sedimentation through 6\% dextran T500 (Pharmacia, Uppsala, Sweden) for $30 \mathrm{~min}$ at $37^{\circ} \mathrm{C}$, and centrifugation through FicollHypaque at $400 \mathrm{~g}$ for $30 \mathrm{~min}$. The agglutinating effects of similar concentrations of AMS or NSS on aliquots of equal numbers of macrophages and PMN was assessed on glass slides. To determine the reactivity of fluoresceinated AMS with rabbit cells, $2 \times 10^{6}$ cells in MEM were reacted with dilutions of a fluoresceinated AMS at $37^{\circ} \mathrm{C}$ for $30 \mathrm{~min}$. Controls included a suspension of normal kidney cortical cells, PMN, and spleen cells. Suspensions of the washed cells were examined by fluorescence microscopy.

To define the effect of AMS on macrophage adherence, aliquots of $10^{6}$ peritoneal macrophages in MEM with $1 \%$ FCS were placed into T25 flasks (Falcon Labware Division, Becton, Dickinson \& Co. Rutherford, N. J.). AMS and NSS were added to final concentrations of 10,3 , and $1 \%$. Spreading was observed qualitatively after $1 \mathrm{~h}$ at $37^{\circ} \mathrm{C}$. At that time the flasks were rinsed vigorously four times with Hank's buffered saline (Flow Laboratories) to remove nonadherent cells. After 20 min the adherent cells were removed $(2.5 \%$ trypsin, Flow Laboratories) and counted. The experiment was repeated three times and the results averaged.

The effect of the AMS or NSS (1 or 3\%) on phagocytosis of latex particles (1.1 $\mu \mathrm{m}$, Sigma Chemical Co., St. Louis, Mo.) was studied using aliquots of blood monocytes and PMN. After incubation at room temperature for $10 \mathrm{~min}$, latex particles were added to the cells and gently mixed for $20 \mathrm{~min}$.
Washed cells were smeared on glass slides and stained with Wright's stain, and the number of latex particles taken up per cell was determined under oil immersion microscopy with 10 replicate counts per smear averaged.

The viability of cells treated with AMS or NSS was determined with fluorescein diacetate (30) (Sigma Chemical Co.). Dilutions of AMS or NSS (1, 3, or 10\%) were added to $1.2 \times 10^{6}$ peritoneal macrophages in $500 \mu \mathrm{M} \mathrm{MEM-1 \%}$ FCS for $30 \mathrm{~min}$ at room temperature. $2 \mu \mathrm{l}$ of fluorescein diacetate $(5 \mathrm{mg} / \mathrm{ml})$ was added and incubated for $15 \mathrm{~min}$ at room temperature, after which the cells were washed and examined by fluorescence microscopy. The means of five replicate counts on each of two slides were obtained in two different experiments. Viable cells hydrolyze fluorescein diacetate releasing fluorescein which, being polar, is unable to diffuse rapidly from live cells.

Assessment In vivo. Six normal rabbits were injected with $200 \mathrm{mg}$ i.p. of AMS every $12 \mathrm{~h}$ for $3 \mathrm{~d}$. Blood was drawn for total and differential leukocyte counts before the initial injection and then 2,4 , and $12 \mathrm{~h}$ later. Counts were repeated 2 and $12 \mathrm{~h}$ after each subsequent dose. Hematocrits and platelet counts were also determined $4 \mathrm{~h}$ after each dose. Six control rabbits were injected intraperitoneally with an equal quantity of NSS and similar measurements made. Urine was collected over each $24 \mathrm{~h}$ period for the quantitation of proteinuria; the rabbits in both groups were killed after $3 \mathrm{~d}$ and histologic assessment made of the kidneys, spleen, liver, heart, and lung. Tissue fixation of AMS globulin at $6 \mathrm{~h}$ was studied in other rabbits by fluorescence microscopy.

Morphologic assessment. For light microscopy, Bouin's fixed tissue was paraffin embedded, sectioned at $2 \mu \mathrm{m}$, and stained with hematoxylin and eosin and periodic acidSchiff reagent. PMN were expressed as the mean per 20 glomerular sections. Tissue for transmission electron microscopy was fixed for $1 \mathrm{~h}$ in modified Karnovsky's fixative followed by dehydration and embedding in Spurr's resin. Ultrathin sections were cut and stained with uranyl acetate and lead citrate, and viewed with a Hitachi $11 \mathrm{E}$ electron microscope (Perkin-Elmer Corp., Scientific Instrument Dept., Mountain View, Calif.) at an accelerating voltage of $75 \mathrm{kV}$. At least three glomeruli from each rabbit were assessed. Tissues for immunofluorescence were snap frozen, sectioned, fixed in ether-alcohol, and stained with monospecific fluoresceinated antisera to detect rabbit IgG, C3, and, where appropriate, sheep IgG, horse IgG, and BSA (31). AMS was fluoresceinated as previously described (31).

\section{RESULTS}

Characterization of the PAGBMN model. The subnephritogenic dose of horse anti-rabbit GBM antibody did not induce proteinuria (mean $6 \mathrm{mg} / 15 \mathrm{~h}$; range 3-12) or glomerular injury. After rabbit anti-horse gamma globulin antibody administration proteinuria regularly occurred (mean $299 \mathrm{mg} / \mathrm{d}$; range 40-1,036) (Table I). Only occasional PMN were observed at all time points assessed throughout the evolution of PAGBMN (Table I). $12 \mathrm{~h}$ after the administration of rabbit anti-horse gamma globulin antibody, macrophages were detected in culture, proteinuria was found, and histologic lesions were evident.

$24 \mathrm{~h}$ after administration of rabbit anti-horse gamma globulin antibody, PAGBMN was characterized by a severe diffuse endocapillary glomerulonephritis in- 
TABLE I

Evolution of the PAGBMN Model

\begin{tabular}{|c|c|c|c|c|c|}
\hline \multicolumn{3}{|c|}{ Time } & \multirow[t]{2}{*}{$\begin{array}{l}\text { PMN/glomerular } \\
\text { cross section }\end{array}$} & \multirow[t]{2}{*}{$\begin{array}{l}\text { Macrophages/ } \\
\text { glomerulus }\end{array}$} & \multirow[t]{2}{*}{$\begin{array}{c}\text { Proteinuria } \\
\text { mg/time interval }\end{array}$} \\
\hline & $h$ & $n$ & & & \\
\hline 0 & & 30 & $\begin{array}{r}0.4 \pm 0.2 \\
(0-2)\end{array}$ & $\begin{array}{c}0.2 \pm 0.1 \\
(0-1)\end{array}$ & $\begin{array}{c}5 \pm 2 \\
(2-11)\end{array}$ \\
\hline \multicolumn{6}{|c|}{$\begin{array}{l}\text { Horse anti-rabbit GMB antibody } \\
\text { administered }\end{array}$} \\
\hline 2 & & 4 & $\begin{array}{c}1.8 \pm 0.9 \\
(0-3)\end{array}$ & $\begin{array}{l}3.0 \pm 2.8 \\
(1-7)\end{array}$ & ND \\
\hline 15 & & 4 & $\begin{array}{c}1.2 \pm 0.7 \\
(0-2)\end{array}$ & $\begin{array}{l}5.4 \pm 3.9 \\
(2-11)\end{array}$ & $\begin{array}{c}6 \pm 4 \\
(3-12)\end{array}$ \\
\hline \multicolumn{6}{|c|}{$\begin{array}{l}\text { Rabbit anti-horse gamma globulin } \\
\text { antibody administered }\end{array}$} \\
\hline 17 & & 4 & $\begin{array}{c}1.6 \pm 0.8 \\
(0-3)\end{array}$ & $\begin{array}{c}5.5 \pm 3.1 \\
(3-12)\end{array}$ & ND \\
\hline 27 & & 4 & $\begin{array}{c}1.8 \pm 1.2 \\
(0-3)\end{array}$ & $\begin{array}{c}16.6 \pm 8.9 \\
(4-40)\end{array}$ & $\begin{array}{c}46 \pm 28 \\
(12-85)\end{array}$ \\
\hline 39 & & 14 & $\begin{array}{c}0.8 \pm 0.3 \\
(0-2)\end{array}$ & $\begin{array}{c}55.6 \pm 31.4 \\
(16-144)\end{array}$ & $\begin{array}{c}299 \pm 174 \\
(40-1036)\end{array}$ \\
\hline
\end{tabular}

After an initial biopsy and 24-h urine collection, groups of rabbits were killed at $2,15,17,27$, and $39 \mathrm{~h}$. Subsequent urine collections were for the first $15 \mathrm{~h}$, from 15-27 h, and from 27-39 h. $\mathrm{ND}$, not detectable. Data are mean $\pm \mathrm{SD}$, with the range in parentheses.

volving all glomeruli to variable degrees (Fig. 1A). Lobular clustering of cells within loops was evident in many glomeruli. Few PMN were seen. No tubulointerstitial changes were noted. Ultrastructurally, the endocapillary glomerulonephritis was comprised of two principal changes of a cellular nature. Endothelial cytoplasm was swollen and many mononuclear cells occupied the glomerular loops, often compromising the lumens (Fig. 1B). The mononuclear cells often had the features of macrophages but it was not always possible to differentiate them from endothelial cells. Occasionally, macrophages could be observed directly adhering to areas of denuded GBM and elevating the endothelium from it (Fig. 1C). Visceral epithelial cell cytoplasm was spread in some sites due to effacement of the foot processes. By immunofluorescence microscopy, linear deposition of horse IgG, rabbit IgG, and C3 was seen along the GBM. Other renal structures did not show these immune reactants. Large numbers of macrophages (mean 55.6 macrophages per glomerulus; range 16-144) (Table I) were observed in the outgrowths of PAGBMN glomeruli using glomerular cell culture.

Effect of nitrogen mustard on PAGBMN. Rabbits treated with nitrogen mustard failed to develop the histologic lesion of PAGBMN. Macrophage accumulation did not occur (mean 1.4 macrophages per glomerulus; range 0-2) (Table II) and proteinuria was prevented (mean $7 \mathrm{mg} / \mathrm{d}$; range 3-12).

Effect of cobra venom factor on PAGBMN. Cobra venom factor induced marked and persistent depletion of $\mathrm{CH}_{50}$ and serum C3 levels to $<10 \%$ of that measured before PAGBMN induction. Immunofluorescence staining of the glomeruli was negative for $\mathrm{C} 3$, whereas staining for horse IgG and rabbit IgG was similar in distribution and extent to that in rabbits without complement depletion. Complement depletion afforded no protection from the induction of injury as seen by light and electron microscopy. The numbers of macrophages per glomerulus (mean 63 macrophages per glomerulus; range 32-106) (Table II) were similar to those detected in glomeruli from untreated controls. Complement depletion did not prevent the development of proteinuria (mean $509 \mathrm{mg} / 24 \mathrm{~h}$; range 200 1,040) (Table II). The neutrophilia known to be induced by cobra venom factor (23) was observed in these rabbits.

\section{AMS: characterization and use in PAGBMN}

Effect of AMS on peritoneal macrophages and leukocytes from normal rabbits in vitro. AMS at $10 \%$ concentration caused aggregation of peritoneal macrophages and prevented their adherence. Lower con- 


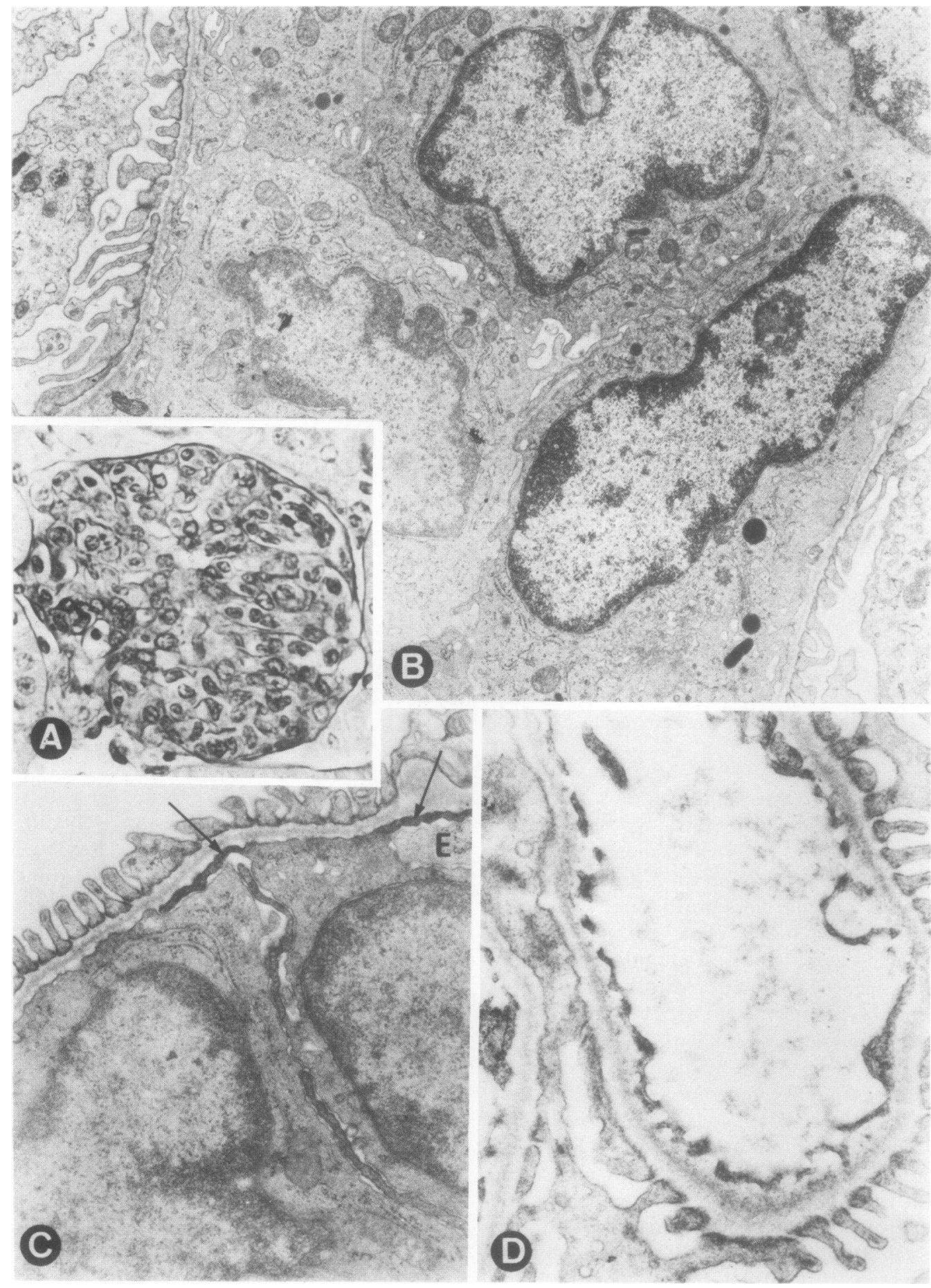

FIGURE 1 Glomerular morphology in PAGBMN. (A) Glomerular histology of untreated PAGBMN; a marked, diffuse, endocapillary glomerulonephritis is present $(\times 250)$. (B) Electron photomicrograph of a glomerular loop from an untreated PAGBMN rabbit; cells with the appearances of macrophages occupy the capillary lumen $(M)(\times 20,000)$. (C) Electron photomicrograph of the periphery of a loop from a rabbit with PAGBMN; macrophages are present in direct contact with GBM and extending microvilli beneath adjacent macrophage (arrows) and endothelium (E) $(\times 27,700)$. (D) Electron photomicrograph of glomerular loops from a PAGBMN rabbit treated with AMS; the loops are free of circulating leukocytes but residual endothelial changes persist $(\times 24,000)$. 
TABLE II

Treatment of Rabbits Developing PAGBMN: Effect on Proteinuria and Macrophage Number per Glomerulus

\begin{tabular}{|c|c|c|c|}
\hline \multirow[b]{2}{*}{ Treatment } & \multicolumn{2}{|c|}{ Proteinuria } & \multirow[b]{2}{*}{$\begin{array}{l}\text { Macrophages/ } \\
\text { glomerulus }\end{array}$} \\
\hline & $\begin{array}{l}0-15 \text { h post- } \\
\text { HRGMB }\end{array}$ & $\begin{array}{l}0-24 \text { h post- } \\
\text { RHGG }\end{array}$ & \\
\hline$(n)$ & \multicolumn{2}{|c|}{ mg/time interval } & \\
\hline None (14) & $\begin{array}{c}5 \\
(2-19)\end{array}$ & $\begin{array}{c}299 \\
(40-1,036)\end{array}$ & $\begin{array}{c}56 \\
(16-144)\end{array}$ \\
\hline NSS (6) & $\begin{array}{c}4 \\
(2-12)\end{array}$ & $\begin{array}{c}335 \\
(55-975)\end{array}$ & $\begin{array}{c}52 \\
(27-69)\end{array}$ \\
\hline $\operatorname{AMS}(12)$ & $\begin{array}{c}6 \\
(1-13)\end{array}$ & $\begin{array}{c}10 \\
(2-24)\end{array}$ & $\begin{array}{c}5 \\
(2-7)\end{array}$ \\
\hline $\mathrm{CVF} \S(7)$ & $\begin{array}{c}4 \\
(1-36)\end{array}$ & $\begin{array}{c}509 \\
(200-1,040)\end{array}$ & $\begin{array}{c}63 \\
(32-106)\end{array}$ \\
\hline Nitrogen mustard (6) & $\begin{array}{c}3 \\
(1-4)\end{array}$ & $\begin{array}{c}7 \\
(3-12)\end{array}$ & $\begin{array}{c}1.4 \\
(0-2)\end{array}$ \\
\hline
\end{tabular}

Results are expressed in means and ranges.

* HRGBM, horse anti-rabbit GBM antibody.

$\$$ RHGG, rabbit anti-horse gamma globulin antibody.

$\$ C V F$, cobra venom factor.

centrations impaired adherence and spreading of these cells compared with the effects of the same concentrations of NSS (Table III). Latex phagocytosis by macrophages was reduced by AMS but phagocytosis by PMN was not affected (Table III). As assessed by fluorescein diacetate staining, AMS reduced the numbers of viable peritoneal macrophages but had no effect on the numbers of viable PMN (Table III).

Fluoresceinated AMS stained peritoneal macrophages but had no reaction with a heterogeneous suspension of normal kidney cortical cells or any renal structures, including the mesangia, of normal rabbit kidney tissue sections.

Effect of AMS on normal rabbits in vivo. A brief reduction in total leukocyte counts was observed in the groups of six normal rabbits given equal doses of AMS or NSS, respectively. PMN and lymphocytes were reduced to similar levels $2 \mathrm{~h}$ after treatment with both sera, returning to preinjection values by $4 \mathrm{~h}$ (Table IV). Monocyte levels were transiently reduced after administration of NSS (mean 34\%) but returned to the normal range by $4 \mathrm{~h}$. AMS, however, produced a marked acute reduction in the monocyte count (mean $91 \%$ ), which was sustained, so that even at $12 \mathrm{~h}$ a mean reduction of $62 \%$ was still observed. Similar effects on each of the cell types were seen after each dose over the $3 \mathrm{~d}$.

No effects of AMS were observed at $4 \mathrm{~h}$ on hematocrit, platelet count, or $\mathrm{CH}_{50}$ levels. Base-line hematocrit (mean 46\%; range 42-51), platelet count (mean $5.1 \times 10^{5} / \mathrm{mm}^{3}$; range $\left.3.6-8.5 \times 10^{5}\right), \mathrm{CH}_{50}$ (mean $32 \mathrm{U} / \mathrm{ml}$; range 21-42), were comparable to hematocrit (mean 48\%, range 42-53), platelet count (mean $5.5 \times 10^{5} / \mathrm{mm}^{3}$; range $4.1-8.5 \times 10^{5}, \mathrm{CH}_{50}$ (mean $35 \mathrm{U} / \mathrm{ml}$; range $19-40)$ at $4 \mathrm{~h}$. The NSS similarly had no effect on these parameters.

AMS did not produce proteinuria in excess of normal base-line levels, induce renal lesions, or produce histologic changes in the spleen, liver, heart, or lung when given to normal rabbits. Deposits of sheep IgG were seen on intrasinusoidal cells in the liver and cells within the walls and lumena of lung alveoli. No sheep IgG bound to the kidney.

Effect of AMS on the development of PAGBMN. The effects of AMS on peripheral leukocyte counts in the 12 rabbits developing PAGBMN were the same as in normal rabbits. Persistent depression in monocyte counts was observed extending to sacrifice, with a

TABLE III

Effect of AMS and NSS on Macrophage Function In Vitro

\begin{tabular}{|c|c|c|c|c|c|c|}
\hline & \multicolumn{2}{|c|}{ Adherence and spreading } & \multicolumn{2}{|c|}{ Viability } & \multirow{2}{*}{\multicolumn{2}{|c|}{ Latex phagocytosis-particles/cell }} \\
\hline & \multirow{2}{*}{$\begin{array}{c}\text { Macrophages } \\
\text { adhering (mean) }\end{array}$} & \multirow{2}{*}{$\begin{array}{l}\text { Macrophage } \\
\text { spreading }\end{array}$} & \multirow{2}{*}{$\begin{array}{l}\text { Macrophages } \\
\text { viable (mean) }\end{array}$} & \multirow{2}{*}{$\begin{array}{c}\text { PMN } \\
\text { viable (mean) }\end{array}$} & & \\
\hline & & & & & Monocytes & PMN \\
\hline & $\%$ & & & & & \\
\hline \multicolumn{7}{|l|}{ AMS } \\
\hline $10 \%$ & 1 & Absent & 10 & 92 & ND & ND \\
\hline $3 \%$ & 2 & Markedly impaired & 40 & 89 & $0.4 *(0-1)$ & $3.9(1-7)$ \\
\hline $1 \%$ & 21 & Impaired & 80 & 90 & $3.1 \quad(1-4)$ & $4.2(2-6)$ \\
\hline \multicolumn{7}{|l|}{ NSS } \\
\hline $10 \%$ & 41 & Normal & 91 & 91 & ND & ND \\
\hline $3 \%$ & 38 & Normal & 89 & 92 & $3.6(1-5)$ & $4.2(2-6)$ \\
\hline $1 \%$ & 35 & Normal & 85 & 88 & $3.8 \quad(1-5)$ & $3.8(1-5)$ \\
\hline
\end{tabular}

ND, not done.

* Particles/cell as mean and range. 
TABLE IV

Effects of AMS or NSS on Leukocyte Count in Normal Rabbits*

\begin{tabular}{|c|c|c|c|c|c|c|}
\hline \multirow[b]{2}{*}{ Time } & \multicolumn{2}{|c|}{$\mathrm{PMN} / \mathrm{cm}^{3}$} & \multicolumn{2}{|c|}{ Lymphocytes $/ \mathrm{cm}^{3}$} & \multicolumn{2}{|c|}{ Monocytes $/ \mathrm{cm}^{3}$} \\
\hline & AMS & NSS & AMS & NSS & AMS & NSS \\
\hline \multicolumn{7}{|l|}{$h$} \\
\hline 0 & $\begin{array}{c}5,360 \pm 1,689 \\
(3,969-8,313)\end{array}$ & $\begin{array}{c}6,090 \pm 1,984 \\
(3,914-8,616)\end{array}$ & $\begin{array}{c}4,331 \pm 1,349 \\
(2,562-5,817)\end{array}$ & $\begin{array}{c}3,898 \pm 1,206 \\
(2,883-5,367)\end{array}$ & $\begin{array}{c}292 \pm 126 \\
(208-510)\end{array}$ & $\begin{array}{c}298 \pm 132 \\
(190-496)\end{array}$ \\
\hline 2 & $\begin{array}{c}3,413 \pm 1,209 \\
(2,908-6,947)\end{array}$ & $\begin{array}{c}4,610 \pm 1,437 \\
(3,118-6,985)\end{array}$ & $\begin{array}{c}3,290 \pm 1,267 \\
(2,219-5,889)\end{array}$ & $\begin{array}{c}3,402 \pm 1,431 \\
(2,652-6,106)\end{array}$ & $\begin{array}{l}26 \pm 13 \\
(0-79)\end{array}$ & $\begin{array}{c}196 \pm 88 \\
(130-410)\end{array}$ \\
\hline 4 & $\begin{array}{c}6,237 \pm 1,892 \\
(3,764-8,718)\end{array}$ & $\begin{array}{c}6,322 \pm 1,951 \\
(4,117-8,907)\end{array}$ & $\begin{array}{c}4,106 \pm 1,108 \\
(2,617-5,799)\end{array}$ & $\begin{array}{c}4,098 \pm 1,611 \\
(2,615-6,305)\end{array}$ & $\begin{array}{l}41 \pm 18 \\
(0-86)\end{array}$ & $\begin{array}{c}275 \pm 121 \\
(120-520)\end{array}$ \\
\hline 12 & $\begin{array}{c}6,111 \pm 1,792 \\
(4,106-8,244)\end{array}$ & $\begin{array}{c}5,934 \pm 1,831 \\
(3,982-7,934)\end{array}$ & $\begin{array}{c}4,368 \pm 1,228 \\
(2,719-5,873)\end{array}$ & $\begin{array}{c}4,208 \pm 1,517 \\
(2,915-5,937)\end{array}$ & $\begin{array}{l}111 \pm 38 \\
(40-180)\end{array}$ & $\begin{array}{c}294 \pm 129 \\
(200-510)\end{array}$ \\
\hline
\end{tabular}

The effect of equal doses of intraperitoneally administered sheep AMS or NSS on the levels of PMN, lymphocytes, and monocytes in groups of six normal rabbits.

* Data are mean $\pm \mathrm{SD}$, with the range in parentheses.

mean of $94 \%$ and $69 \%$ depletion of the preimmunization values at 2 and $12 \mathrm{~h}$ after the final AMS dose. Deposition of rabbit anti-horse gamma globulin antibody was unaffected (mean $6.1 \mu \mathrm{g}$ rabbit anti-horse gamma globulin antibody/g kidney; range $4.8-7.5$ ) by the administration of $100 \mathrm{mg}$ of AMS. In rabbits given AMS significant proteinuria did not occur (mean $10 \mathrm{mg} /$ $24 \mathrm{~h}$; range 2-24) (Table II). Rabbits given NSS developed a similar degree of proteinuria (mean 335 $\mathrm{mg} / 24 \mathrm{~h}$; range 55-975) to untreated controls (Table II) and had morphologic changes indistinguishable from untreated PAGBMN rabbits (Fig. 2A).

Rabbits treated with AMS all showed a pronounced amelioration of the histologic lesion and in many cases the glomeruli appeared nearly normal at the light microscopic level (Fig. 2B). By electron microscopy, the AMS-treated rabbits had residual minor endothelial cell cytoplasmic changes. These consisted of occasional areas of separation from the GBM and some evidence of cytoplasmic swelling (Fig. 1D). Mononuclear cells were only rarely evident within the lumena, or marginated, and the glomeruli were usually normocellular. There were no differences observed in the immunofluorescence staining pattern for horse IgG, rabbit IgG, and rabbit C3 in the glomeruli from animals with PAGBMN or PAGBMN treated with NSS or AMS.

Very few macrophages were found in the outgrowths of cultured glomeruli from AMS-treated rabbits (mean 5 macrophages per glomerulus; range 2-7) (Table II). Glomeruli from NSS-treated rabbits showed a mean of 52 macrophages per glomerulus; (range 27-69) (Table II), similar to untreated controls.

Effects of AMS on AcSS. The globulin fractions of AMS and NSS contained barely detectable and equal amounts of albumin by gel diffusion, indicating that their use would not be expected to affect the immune complex load of the model by adding crossreacting albumin antigens. The extent of histologic injury in AcSS is dependent on the day of immune elimination (26), and this was similar for the three groups of rabbits that were randomly allocated to treatment with either AMS (mean $10.5 \mathrm{~d}$; range 9-12) or NSS (mean $9.8 \mathrm{~d}$; range $9-11$ ) or to no treatment (mean $10.3 \mathrm{~d}$; range 9-12) (Table V). The levels of BSA-anti-BSA circulating immune complexes measured daily for the $3 \mathrm{~d}$ before immune elimination were also similar (Fig. 3). The granular deposition of immune reactants (BSA, rabbit IgG, and C3) in the glomeruli was indistinguishable in the three groups. The timing of maximum proteinuria was also the same in each group (Table III). Thus, the AMS did not measurably alter any role for macrophages in the anti-BSA immune response or the clearance of circulating immune complexes that could have changed the basic immunopathogenic process.

The effects of AMS and NSS on the leukocyte counts of four rabbits developing AcSS were similar to those observed in normal and PAGBMN rabbits with persistent depletion of monocytes of 72 and $58 \%$ mean at 2 and $12 \mathrm{~h}$ after the final AMS dose. Proteinuria was reduced to near normal levels in the AMS-treated rabbits (mean $41 \mathrm{mg} / 24 \mathrm{~h}$ ) (Table V). One treated rabbit had a maximum protein excretion of $161 \mathrm{mg} / 24 \mathrm{~h}$, while the remaining seven rabbits had 24 -h protein excretion of $<48 \mathrm{mg}$. The untreated and NSS-treated rabbits had mean 24-h protein excretions of $540 \mathrm{mg}$ (range 248-849) and $516 \mathrm{mg}$ (range 200-991), respectively.

Untreated rabbits and those treated with NSS all 

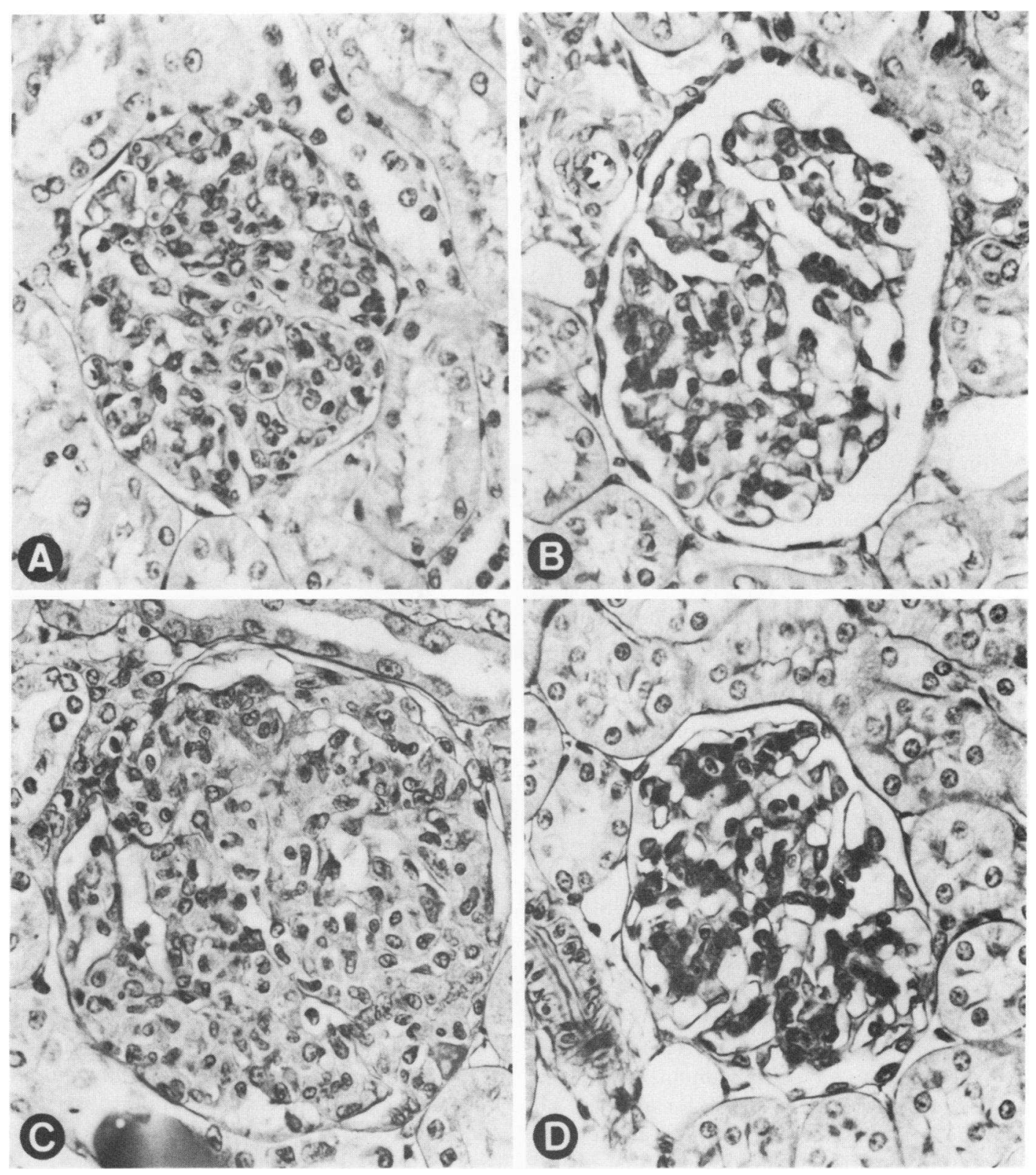

FIGURE 2 The glomerular histology of treated PAGBMN and AcSS (A) A PAGBMN rabbit treated with NSS; the lesion was not affected $(\times 320)$. (B) A PAGBMN rabbit treated with AMS; glomerular injury was profoundly reduced $(\times 320)$. (C) An AcSS rabbit treated with NSS; there was no effect on the endocapillary lesion $(\times 320)$. (D) An AcSS rabbit treated with AMS; glomerular structure and cellularity was almost normal $(\times 320)$.

developed a severe endocapillary glomerulonephritis (Fig. 2C). However, all the AMS-treated rabbits showed a very marked reduction in the glomerular injury observed at the light microscopic level (Fig. 2D), although one developed a mild endocapillary lesion.

The glomerular ultrastructure of NSS-treated and untreated rabbits was similar. Pronounced intracapillary mononuclear cell accumulation and endothelial cell cytoplasmic prominence formed the basis of the lesion
(Fig. 4A). There was also a mild increase in the mesangia. Epithelial foot process spreading was a common finding. Infrequent electron dense deposits were observed on both sides of the basement membrane as previously reported (15). Rabbits treated with AMS had a pattern of subendothelial and subepithelial electron dense deposits similar to untreated controls but glomerular hypercellularity was considerably reduced (Fig. 4B). Some degree of endothelial swelling 
TABLE V

Effect of Treatment of Rabbits with Acss

\begin{tabular}{|c|c|c|c|c|}
\hline \multirow[b]{2}{*}{ Treatment } & \multirow{2}{*}{$\begin{array}{c}\text { Day of } \\
\text { immune } \\
\text { elimination }\end{array}$} & \multicolumn{2}{|c|}{ Proteinuria } & \multirow{2}{*}{$\begin{array}{c}\text { Number of } \\
\text { macrophages } \\
\text { per glomerulus }\end{array}$} \\
\hline & & $\begin{array}{c}\text { Maximum } \\
\mathrm{mg} / 24 \mathrm{~h}\end{array}$ & $\begin{array}{c}\text { Day of } \\
\text { maximum }\end{array}$ & \\
\hline \multicolumn{5}{|l|}{$(n)$} \\
\hline None (6) & $\begin{array}{c}10.3 \\
(9-12)\end{array}$ & $\begin{array}{c}540 \\
(248-849)\end{array}$ & $\begin{array}{c}9.9 \\
(9-11)\end{array}$ & $\begin{array}{c}128 \\
(60-246)\end{array}$ \\
\hline NSS (6) & $\begin{array}{c}9.8 \\
(9-11)\end{array}$ & $\begin{array}{c}516 \\
(200-991)\end{array}$ & $\begin{array}{c}9.3 \\
(8-11)\end{array}$ & $\begin{array}{c}126 \\
(40-251)\end{array}$ \\
\hline AMS (8) & $\begin{array}{c}10.5 \\
(9-12)\end{array}$ & $\begin{array}{c}41 \\
(3-161)\end{array}$ & $\begin{array}{c}9.7 \\
(9-11)\end{array}$ & $\begin{array}{c}8 \\
(1-44)\end{array}$ \\
\hline $\mathrm{CVF}^{*}(6)$ & $\begin{array}{c}10.0 \\
(9-12)\end{array}$ & $\begin{array}{c}481 \\
(223-783)\end{array}$ & $\begin{array}{c}9.5 \\
(8-11)\end{array}$ & $\begin{array}{c}89 \\
(41-178)\end{array}$ \\
\hline
\end{tabular}

All results expressed in mean and range.

* CVF, cobra venom factor.

persisted in some loops but separation from the GBM was rare. Epithelial cell foot processes were in the main discrete, and not effaced. Mononuclear cells were seen only very occasionally within the loops.

Large numbers of macrophages were observed in the outgrowths of glomeruli isolated from both untreated (mean 128 macrophages per glomerulus; range 60-246) and NSS-treated rabbits (mean 126 macrophages per glomerulus; range 40-251) (Table V). The number of macrophages detected in glomerular outgrowths from AMS-treated rabbits was markedly reduced (mean 8 macrophages per glomerulus; range 1-44). The rabbit with the mild glomerular lesion had 44 macrophages per glomerulus. The remaining AMS-treated rabbits had $<13$ macrophages per glomerulus.

Effect of cobra venom factor on AcSS. In the seven AcSS animals given cobra venom factor, the levels of C3 were reduced by $>90 \%$ for at least $3 \mathrm{~d}$ before immune elimination. The pattern and extent of BSA and IgG deposition was similar to that of untreated rabbits; however, glomerular C3 deposition was prevented. The glomerular histologic and ultrastructural appearance in the six cobra venom factortreated rabbits that eliminated the administered BSA between 9 and $12 \mathrm{~d}$ was similar to that in the NSStreated and untreated AcSS groups. The levels of circulating immune complexes were comparable to those measured in AMS- and NSS-treated rabbits (Fig. 3). The timing of maximum proteinuria (mean day 9.5; range 8-11) and extent of the proteinuria (mean $481 \mathrm{mg} / 24 \mathrm{~h}$; range 223-783) was similar to that observed in both the untreated and NSS-treated groups (Table V). The cobra venom factor-treated rabbits had a mean of 89 macrophages per glomerulus (range 41-

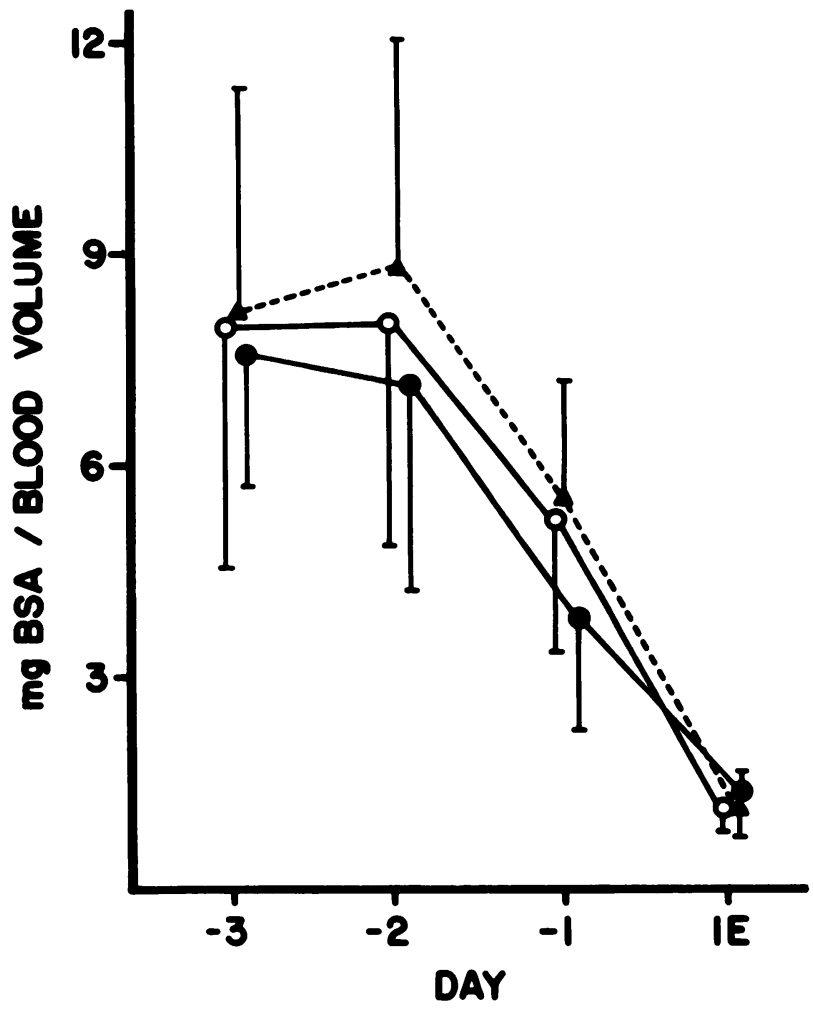

Figure 3 The quantitation of circulating radiolabeled-BSAcontaining immune complexes in treated AcSS rabbits detected by ammonium sulfate precipitation. Values expressed in terms of complexed radiolabeled-BSA per total blood volume. Values represent means \pm SD. $\triangle$, AMS; $O$, NSS; , CVF, cobra venom factor.

178) that was not significantly lower than either NSStreated or untreated rabbits when assessed by Wilcoxson ranking analysis (32).

Effect of AMS on the heterologous phase of anti-GBM antibody-mediated glomerulonephritis. Both untreated rabbits $(n=6)$ and those treated with AMS $(n=6)$ developed marked proteinuria (untreated mean $1,105 \mathrm{mg} / 24 \mathrm{~h}$; range $340-2,512$; AMStreated mean $996 \mathrm{mg} / 24 \mathrm{~h}$; range 400-2,167). A moderately proliferative glomerulonephritis was observed in both groups with few PMN at $24 \mathrm{~h} /$ glomerular section (AMS-treated, mean 1.5; range 0-2; untreated, mean 1.2; range $0-2$ ). There also was no difference between the number of PMN per glomerular section at $2 \mathrm{~h}$ in rabbits treated with AMS or left untreated (AMS-treated mean 7.1 ; range 5-8; untreated, mean 6.6; range 5-7). Macrophage outgrowth per glomerulus was not striking in this model (mean 12; range 9-16 in untreated rabbits, mean 3 , range $0-7$ in AMStreated rabbits).

It was evident that the AMS did not affect the histologic or functional injury in this lesion. The 

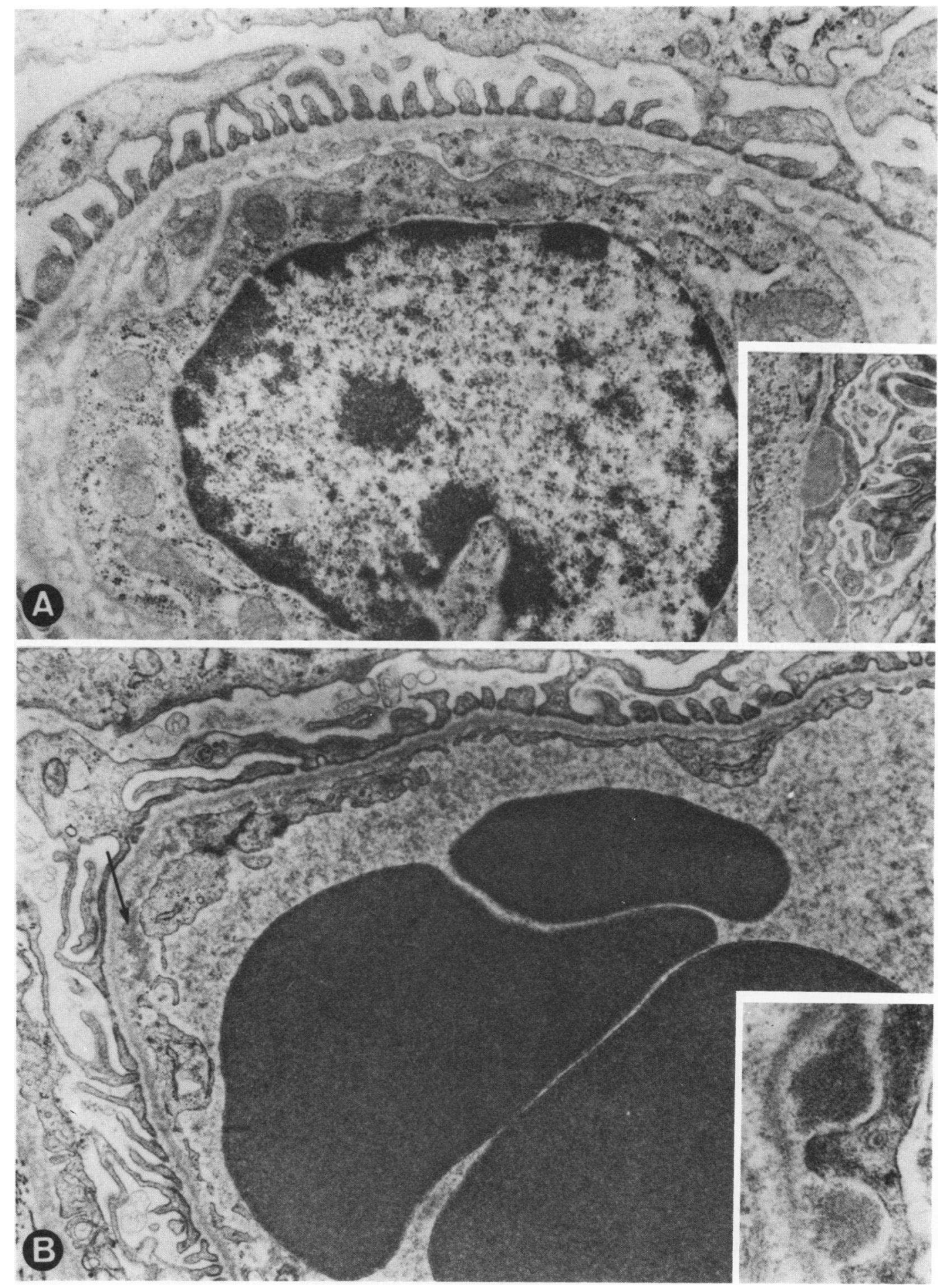

FIGURE 4 Glomerular morphology in AcSS: (A) An electron photomicrograph of a glomerular loop from an untreated rabbit; a mononuclear cell with macrophage characteristics is shown in the lumen $(\times 36,300)$. The inset shows subepithelial electron dense deposits $(\times 23,900)$. (B) An electron photomicrograph of a glomerular loop from an AMS-treated rabbit; the lumen is patent and contains erythrocytes. Small subendothelial deposits are indicated by the arrow. $(\times 32,300)$ The inset shows subepithelial electron dense deposits seen in an AMS-treated rabbit $(\times 35,000)$. 
PMN dependence of the lesion was suggested when similar rabbits $(n=6)$ treated with nitrogen mustard developed only minimal proteinuria over the $24 \mathrm{~h}$ after horse anti-rabbit GBM antibody (mean $25 \mathrm{mg} / 24 \mathrm{~h}$; range 10-35) and showed no histologic lesion. A mean of only two macrophages per glomerulus; range 0-4, were recovered from these rabbits on culture.

\section{DISCUSSION}

The definition of the phlogogenic potential of mediator systems such as the PMN $(1,2)$, complement $(1,3)$, fibrin (4), and platelets $(5,33)$ in immune glomerular injury has relied heavily on selective mediator depletion. Individually, the mediators contribute to variable degrees in different types of experimental nephritis. Thus complement depletion prevents some forms of heterologous anti-GBM disease (1), but during AcSS (3) and the autologous phase of anti-GBM disease (34) this maneuver affords no protection. PMN depletion produces considerable protection in some heterologous (1) and autologous (2) phases of antiGBM disease, although PMN depletion in AcSS (6) has no effect on the glomerular lesions. In many forms of severe (or chronic) experimental glomerulonephritis, several injurious mediators are brought into play simultaneously so that blocking of any one may be insufficient to abrogate completely the inflammatory damage.

To define the potential for macrophages to contribute to glomerular injury, three models were chosen for study. Large numbers of macrophages have been detected by glomerular cell culture during the autologous phase of anti-GBM antibody-induced injury $(11,29)$. A passive model of autologous anti-GBM injury was used because it is predictable, homogeneous, and rapid in onset, eliminating the variable of the recipient's autologous antibody response to the planted heterologous antibody. PMN were present in only small numbers in the passive model, whereas they are known to be more prominent in the active autologous phase of anti-GBM antibody injury (2). This may be due to greater production and deposition of autologous antibody in the active model. Although PMN were not prominent, the PAGBMN model was shown to be dependent on circulating inflammatory cells by depletion of circulating leukocytes with nitrogen mustard administration. To further exclude any effect of the AMS on PMN participation, the heterologous phase of injury induced by the same heterologous anti-GBM antibody was studied without demonstrable effect. The third experimental model chosen was AcSS, in which macrophages are present in large numbers (15) and PMN and complement participation has been excluded by depletion studies $(3,6)$.
The AMS used in our studies inhibited all macrophage functions tested in vitro; adherence, spreading, and phagocytosis. It rendered the cells metabolically inactive as assessed by viability testing and caused aggregation. In vivo AMS reduced the levels of circulating monocytes without specifically reducing the levels of other leukocytes. The levels of other known inflammatory systems including complement and platelets were not reduced by AMS. The AMS neither specifically influenced the number and function of PMN nor affected the acute heterologous phase of anti-GBM nephritis, a predominantly PMN-mediated glomerular injury. The diminution in glomerular macrophages was associated with a profound reduction in glomerular injury, evidenced by both histologic and electron microscopic study as well as by the functional parameter of urinary protein excretion. Since the AMS caused no detectable change in the underlying immunologic mechanism by influencing binding of anti-GBM antibody or deposition of circulating immune complexes, the beneficial effect of the antibody must be attributed to its ability to reduce macrophage accumulation within glomeruli. The exact mode of action of the AMS in preventing glomerular accumulation of macrophages was not studied, but presumably includes actions such as inhibition of adherence and spreading as noted in vitro, since complete removal of circulating monocytes was not achieved although depressions of $60-70 \%$ or more occurred throughout the study.

The stimuli for macrophage accumulation in PAGBMN and AcSS remain to be elucidated and are independent of complement components depleted by cobra venom factor (Tables II and V). In PAGBMN, the occasional PMN present in the glomeruli were insufficient to produce proteinuria but they may still have been adequate to stimulate macrophage localization. Because few macrophages are observed in the heterologous phase of anti-GBM disease where PMN are more prominent, it is unlikely that PMN provide the only stimulus. In AcSS, the dissociation between $\mathrm{PMN}$ and macrophages is more complete as glomerular damage has been shown to occur despite PMN depletion (6).

The role of lymphocyte-directed macrophage involvement in both models is a question that requires further explanation and study. As macrophage localization occurs after $10 \mathrm{~d}$ in AcSS, it is possible that cellular sensitization to the immunizing antigen may have contributed to the ingress of macrophages to the kidney. Such a sensitized cellular response following deposition of preformed immune complexes in the kidney has recently been described in the rat (35) to cause minimal mononuclear cell infiltration. Cellular sensitization to antigens in PAGBMN seems an un- 
likely explanation for macrophage invasion, due to the extremely short time course of the lesion. A role for lymphocytes or their products, however, cannot be completely excluded, based on the recent observation that lymphocytes appear within glomeruli shortly after administration of heterologous anti-GBM antibody (18). The possible effects of the AMS on lymphocytedirected macrophage function cannot be excluded from the data available in this study $(36,37)$.

The means by which macrophages induce glomerular injury remains to be completely defined. The morphologic findings of endothelial stripping by macrophages associated with direct macrophage basement membrane contact are similar to those observed for the PMN (1), where it is assumed this intimate contact associated with lysosomal enzyme discharge results in loss of basement membrane integrity. Macrophages have an enzyme content which is potentially as capable as that of the PMN in inducing tissue injury $(38-40)$. Recently, macrophages have been shown in vitro to be capable of producing more extensive cleavage of the GBM than equal numbers of PMN (41). These cells, then, have the potential to induce acute injury (38-44), fibrosis (45), or play a role in chronic inflammatory processes (46).

The glomerular endothelial hypertrophy/hyperplasia evident in both models may result from macrophage-endothelial cell interaction. The ability of macrophages to induce responses of a proliferative, secretory, or immunologic nature in other cells is well established $(39,40)$. Potentially most pertinent to glomerular histologic damage is the report that macrophages stimulate endothelial proliferation in delayed hypersensitivity in guinea pigs (47), and the observation that activated macrophages and macrophageconditioned medium can produce vascular proliferation in the guinea pig cornea (48). The glomerular endothelial reaction in the current study was greatly diminished by AMS treatment, related to macrophage depletion. Mild residual endothelial changes were evident at the ultrastructural level in both models. The endothelium is presumably responsive to many stimuli and deposition of immune reactants alone may have been sufficient to produce limited injury.

In conclusion, the current study shows that macrophages are associated with histologic damage and proteinuria in glomerulonephritis produced by the two major immune mechanisms of glomerular injury: deposition of circulating immune complexes, in AcSS, and direct antibody binding to the glomerulus, in PAGBMN. The macrophages seen in forms of glomerular injury where other known mediator systems are involved, may contribute in those situations, although their precise role will be difficult to define. This work strongly suggests that macrophages should be included with the PMN among the inflammatory mediators that can induce acute glomerular injury and proteinuria in experimental glomerulonephritis.

\section{ACKNOWLEDGMENTS}

We are grateful for the technical help of Mrs. Joy Rogers and Ms. Dori Szpisjak. Dr. Richard Ulevitch and Mrs. Katherine Bangs Wesolak provided helpful advice for preparation of cobra venom factor. The secretarial assistance of Mrs. Barbara Neale, Ms. Lena Quinsaat, and Mrs. Pauline Pess, and the photographic services of Ms. Karen Prescott and Mr. Robert Turner are gratefully acknowledged

This work was supported in part by U. S. Public Health Service grants AM-20043, AM-18626, and Al-07007; and Biomedical Research Support grant RRO-5514.

\section{REFERENCES}

1. Cochrane, C. G., E. R. Unanue, and F. J. Dixon. 1965. A role of polymorphonuclear leukocytes and complement in nephrotoxic nephritis. J. Exp. Med. 122: 99-116.

2. Naish, P. F., N. M. Thomson, I. J. Simpson, and D. K. Peters. 1975. The role of polymorphonuclear leukocytes in the autologous phase of nephrotoxic nephritis. Clin. Exp. Immunol. 22: 102-111.

3. Henson, P. M., and C. G. Cochrane. 1971. Acute immune complex disease in rabbits. The role of complement and of a leukocyte-dependent release of vasoactive amines from platelets. J. Exp. Med. 133: 554-571.

4. Naish, P. F., G. N. Penn, D. J. Evans, and D. K. Peters. 1972. The effect of defibrination on nephrotoxic nephritis. Clin. Sci. (Lond.). 42: 643-646.

5. Sindrey, M., T. L. Marshall, and P. Naish. 1979. Quantitative assessment of platelet depletion in the autologous phase of nephrotoxic serum nephritis. Clin. Exp. Immunol. 36: 90-96.

6. Kniker, W. T., and C. G. Cochrane. 1965. Pathogenetic factors in vascular lesions of experimental serum sickness. J. Exp. Med. 122: 83-98.

7. Cochrane, C. G. 1979. Mediation systems in neutrophilindependent immunologic injury of the glomerulus. In Contemporary Issues in Nephrology. C. B. Wilson, B. M. Brenner, and J. H. Stein, editors. Churchill Livingstone, Inc. New York. 3: 106-121.

8. Atkins, R. C., S. R. Holdsworth, E. F. Glasgow, and F. E. Matthews. 1976. The macrophage in human rapidly progressive glomerulonephritis. Lancet. I: 830-832.

9. Schiffer, M. S., and A. F. Michael. 1978. Renal cell turnover studies by $\mathrm{Y}$ chromosome ( $\mathrm{Y}$ body) staining of the transplanted human kidney. J. Lab. Clin. Med. 92: $841-848$.

10. Monga, G., G. Mazzucco, G. Barbiano di Belgiojoso, and G. Busnach. 1979. The presence and possible role of monocyte infiltration in human chronic proliferative glomerulonephritides. Am. J. Pathol. 94: 271-284.

11. Holdsworth, S. R., N. M. Thomson, E. F. Glasgow, J. R. Dowling, and R. C. Atkins. 1978. Tissue culture of isolated glomeruli in experimental crescentic glomerulonephritis. J. Exp. Med. 147: 98-109.

12. Schreiner, G. F., R. S. Cotran, V. Pardo, and E. R. Unanue. 1978. A mononuclear cell component in experimental immunologic glomerulonephritis. J. Exp. Med. 147: 369-384. 
13. Bhan, A. K., E. E. Schneeberger, A. B. Collins, and R. T. McCluskey. 1978. Evidence for a pathogenic role of a cellmediated immune mechanism in experimental glomerulonephritis. J. Exp. Med. 148: 246-260.

14. Hunsicker, L. G., T. P. Shearer, S. B. Plattner, and D. Weisenburger. 1979. The role of monocytes in serum sickness nephritis. J. Exp. Med. 150: 413-425.

15. Holdsworth, S. R., T. J. Neale, and C. B. Wilson. 1980. The participation of macrophages and monocytes in experimental immune complex glomerulonephritis. Clin. Immunol. Immunopathol. 15: 510-524.

16. Striker, G. E., M. Mannik, and M. Y. Tung. 1979. Role of marrow derived monocytes and mesangial cells in removal of immune complexes from renal glomeruli.J. Exp. Med. 149: 127-136.

17. Okumura, K., Y. Kondo, and T. Tada. 1971. Studies on passive serum sickness. I. The glomerular fine structure of serum sickness nephritis induced by preformed antigen-antibody complexes in the mouse. Lab. Invest. 24: 383-391.

18. Kreisberg, J. I., D. B. Wayne, and M. J. Karnovsky. 1979. Rapid and focal loss of negative charge associated with mononuclear cell infiltration early in nephrotoxic serum nephritis. Kidney Int. 16: 290-300.

19. Leibovich, S. J., and R. Ross. 1975. The role of the macrophage in wound repair: a study with hydrocortisone and antimacrophage serum. Am. J. Pathol. 78: 71-100.

20. Hirsch, M. S., G. W. Gary, Jr., and F. A. Murphy. 1969. In vitro and in vivo properties of antimacrophage sera. J. Immunol. 102: 656-661.

21. Gallily, R. 1971. In vitro and in vivo studies of the properties and effects of antimacrophage sera (AMS). Clin. Exp. Immunol. 9: 381-391.

22. Wilson, C. B., F. J. Dixon, J. G. Fortner, and J. Cerilli. 1971. Glomerular basement membrane-reactive antibody in anti-lymphocyte globulin. J. Clin. Invest. 50: 15251535.

23. Cochrane, C. G., H. J. Müller-Eberhard, and B. S. Aikin. 1970. Depletion of plasma complement in vivo by a protein of cobra venom: its effect on various immunologic reactions. J. Immunol. 105: 55-69.

24. Kingsbury, F. B., C. P. Clark, G. Williams, and A. L. Post. 1926. The rapid determination of albumin in urine. J. Lab. Clin. Med. 11: 981-989.

25. Mancini, G., A. O. Carbonara, and J. F. Heremans. 1965. Immunochemical quantitation of antigens by single radial immunodiffusion. Immunochemistry. 2: 235-254.

26. Wilson, C. B., and F. J. Dixon. 1970. Antigen quantitation in experimental immune complex glomerulonephritis. I. Acute serum sickness. J. Immunol. 105: 279-290.

27. Farr, R. S. 1958. A quantitation immunochemical measure of the primary interaction between I* BSA and antibody. J. Infect. Dis. 103: 239-262.

28. Holdsworth, S. R., E. F. Glasgow, N. M. Thomson, and R. C. Atkins. 1978. Tissue culture of isolated human glomeruli. Pathology. 10: 59-67.

29. Thomson, N. M., S. R. Holdsworth, E. F. Glasgow, and R. C. Atkins. 1979. The macrophage in the development of experimental crescentic glomerulonephritis. Am. J. Pathol. 94: 223-240.

30. Rotman, B., and B. W. Papermaster. 1966. Membrane properties of living mammalian cells as studied by enzymatic hydrolysis of fluorogenic esters. Proc. Natl. Acad. Sci. U. S. A. 55: 134-141.

31. Wilson, C. B. 1980. Immunohistopathology of the kidney. In Manual of Clinical Immunology. N. R. Rose, and H. Friedman, editors. American Society for Microbiology, Washington, D. C. 2nd edition. 886-894.

32. Wilcoxson, F. 1945. Individual comparisons by ranking methods. Biometrics Bull. 1: 80.

33. Kniker, W. T., and C. G. Cochrane. 1968. The localization of circulating immune complexes in experimental serum sickness. The role of vasoactive amines and hydrodynamic forces. J. Exp. Med. 127: 119-136.

34. Thomson, N. M., P. F. Naish, I. J. Simpson, and D. K. Peters. 1976. The role of C3 in the autologous phase of nephrotoxic nephritis. Clin. Exp. Immunol. 24: 464473.

35. Bhan, A. K., A. B. Collins, E. E. Schneeberger, and R. T. McCluskey. 1979. A cell-mediated reaction against glomerular-bound immune complexes. J. Exp. Med. 150: 1410-1420.

36. Unanue, E. R. 1980. Cooperation between mononuclear phagocytes and lymphocytes in immunity. N. Engl. J. Med. 303: 977-985.

37. Scher, M. G., D. I. Beller, and E. R. Unanue. 1980. Demonstration of a soluble mediator that induces exudates rich in Ia-positive macrophages. J. Exp. Med. 152: $1684-1678$.

38. Karnovsky, M. L., and J. K. Lazdins. 1978. Biochemical criteria for activated macrophages. J. Immunol. 121: 809-813.

39. Unanue, E. R., D. I. Beller, J. Calderon, J. M. Kiely, and M. J. Stadecker. 1976. Regulation of immunity and inflammation by mediators from macrophages. Am. J. Pathol. 85: 465-478.

40. Unanue, E. R. 1978. The regulation of lymphocyte functions by the macrophage. Immunol. Rev. 40: 227-255.

41. Davies, M., G. A. Coles, and K. T. Hughes. 1979. Monocytes or polymorphonuclear leucocytes: which are the more damaging in glomerulonephritis? Clin. Sci.(Lond.). 57: $18 \mathrm{p}-19 \mathrm{p}$.

42. Unkeless, J. C., S. Gordon, and E. Reich. 1974. Secretion of plasminogen activator by stimulated macrophages. J. Exp. Med. 139: 834-850.

43. Werb, Z., and S. Gordon. 1975. Secretion of a specific collagenase by stimulated macrophages. J. Exp. Med. 142: 346-360.

44. Werb, Z., and S. Gordon. 1975. Elastase secretion by stimulated macrophages. Characterization and regulation. J. Exp. Med. 142: 361-377.

45. Leibovich, S. J., and R. Ross. 1976. A macrophagedependent factor that stimulates the proliferation of fibroblasts in vitro. Am. J. Pathol. 84: 501-513.

46. Spector, W. G. 1974. Chronic inflammation. In The Inflammatory Process. B. W. Zweifach, L. Grant, and R. T. McCluskey, editors. Academic Press, Inc. New York. 2nd edition. 3: 277-290.

47. Polverini, P. J., R. S. Cotran, and M. M. Sholley. 1977. Endothelial proliferation in the delayed hypersensitivity reaction: an autoradiographic study. J. Immunol. 118: 529-532.

48. Polverini, P. J., R. S. Cotran, M. A. Gimbrone, Jr., and E. R. Unanue. 1977. Activated macrophages induce vascular proliferation. Nature (Lond.). 269: 804-806. 